\title{
Survival in Limited Disease Small Cell Lung Cancer According to N3 Lymph Node Involvement
}

\author{
CHRISTINE D. VALAN ${ }^{1,2}$, JENS E. SLAGSVOLD ${ }^{2}$, TARJE ONSØIEN HALVORSEN ${ }^{1,2}$, \\ MARTIN HERJE $^{3}$, ROY M. BREMNES ${ }^{4,5}$, PAAL F. BRUNSVIG ${ }^{6}$, ODD T. BRUSTUGUN ${ }^{7,8}$, \\ ØYSTEIN FLØTTEN ${ }^{9}$, NINA LEVIN ${ }^{2}$, STEIN H. SUNDSTRØM ${ }^{2}$ and BJØRN H. GRØNBERG ${ }^{1,2}$ \\ ${ }^{1}$ Department of Clinical and Molecular Medicine, NTNU, \\ Norwegian University of Science and Technology, Trondheim, Norway; \\ ${ }^{2}$ The Cancer Clinic, St. Olav's Hospital, Trondheim University Hospital, Trondheim, Norway; \\ ${ }^{3}$ Department of Radiology, St. Olav's Hospital, Trondheim University Hospital, Trondheim, Norway; \\ ${ }^{4}$ Department of Oncology, University Hospital of North Norway, Troms $\phi$, Norway; \\ ${ }^{5}$ Department of Clinical Medicine, The Arctic University of Norway, Troms $\phi$, Norway; \\ ${ }^{6}$ Department of Oncology, Oslo University Hospital, The Norwegian Radiumhospital, Oslo, Norway; \\ ${ }^{7}$ Section of Oncology, Drammen Hospital, Vestre Viken Hospital Trust, Drammen, Norway; \\ ${ }^{8}$ Institute of Clinical Medicine, University of Oslo, Oslo, Norway; \\ ${ }^{9}$ Department of Pulmonology, The Arctic University of Norway, Troms $\phi$, Norway
}

\begin{abstract}
Background/Aim: There are several definitions of limited disease $(L D)$ in small cell lung cancer (SCLC), differing with respect to N3 disease accepted. We analyzed patients from a randomized trial comparing two schedules of thoracic radiotherapy (TRT) in LD SCLC to investigate whether there were survival differences between N3 subcategories (n=144). Patients and Methods: Patients with a baseline CT scan available were analysed. Patients received four courses of cisplatin/etoposide and TRT of $45 \mathrm{~Gy} / 30$ fractions (twice daily) or 42 Gy/15 fractions (once daily). Results: Median overall survival (OS) was 23.3 months in the whole cohort. N3-patients $(n=37)$ had shorter survival than those with N0-2 (16.7 vs. 33.0 months; $p<0.001)$. There were no significant OS-differences between the N3 subcategories, but patients with metastases to two or more $N 3$ regions had shorter survival than other N3 patients (13.4 vs. 19.9 months; $p=0.011)$. Conclusion: There were no survival differences between the N3 subcategories, suggesting that all N3 disease should be considered as $L D$.
\end{abstract}

This article is freely accessible online.

Correspondence to: Christine Damgaard Valan, Department of Clinical and Molecular Medicine, NTNU, Norwegian University of Science and Technology, Olav Kyrres gt. 17, 7030 Trondheim, Norway. Tel: +47 93413967, e-mail: christine.valan@icloud.com

Key Words: SCLC, radiotherapy, TNM, staging, prognostic factor.
Chemotherapy is the basis treatment for small cell lung cancer (SCLC). Concurrent radiotherapy improves survival and is offered if all lesions can be included in a radiotherapy field. i.e. limited disease (LD). Patients with more widespread disease are classified as having extended disease (ED) and receive chemotherapy alone (1).

There are, however, several definitions of LD. The first definition was made by the Veterans Administration Lung Study Group (VALSG) in 1957 and defined LD as disease confined to one hemithorax, ipsilateral mediastinal, ipsilateral hilar and ipsilateral supraclavicular lymph node metastases (LNM) (2). The International Association for the Study of Lung Cancer (IASLC) published an article in 1989 recommending that also contralateral mediastinal, contralateral hilar and contralateral supraclavicular lymph nodes should be considered LD, but this recommendation was based on data on lung cancer patients in general and not only SCLC patients (3). Furthermore, several trials published since 1989 have used other definitions of LD. One study excluded patients with contralateral hilar LNM, (4) others excluded both contralateral hilar and contralateral supraclavicular $\operatorname{LNM}(5,6)$.

Internationally, the TNM system is the most widely used classification system for staging of cancer. It is also recommended for staging of SCLC, but still most studies only distinguish between LD and ED. Thus, there is little data available to decide whether all subcategories of N3 disease should be considered as LD; especially with respect to ipsilateral and contralateral supraclavicular LNM. When the latest revision of the TNM for lung cancer was performed, (7) the committee only had complete data on extent of disease and 
treatment on 103 nonsurgical patients who had received concurrent chemo- and radiotherapy for LD SCLC. There were no survival differences between $\mathrm{N}$ categories among nonsurgical patients and there were insufficient data to investigate whether there were survival differences between the different subcategories of N3 disease. Thus, when both the seventh (2009) and eight edition (2015) of the TNM classification of SCLC were published, it was recommended to report the TNM stage in future studies of $\operatorname{SCLC}(7,8)$.

We analyzed patients enrolled in a randomised phase II trial comparing two schedules of thoracic radiotherapy (TRT) in LD SCLC (9). The aims were to investigate the distribution of TNM stage at baseline, and whether there were survival differences between $\mathrm{N}$ categories or the subcategories of $\mathrm{N} 3$ disease.

\section{Materials and Methods}

Approvals. The study was approved by the Regional Committee for Medical Research Ethics in Central Norway, the Norwegian Social Science Data Services and the Norwegian Directorate for Health and Social Affairs.

Patients and treatment. Patients participating in a randomised phase II trial comparing two schedules of TRT in LD SCLC were analysed (9). Eligible patients gave written informed consent; were $\geq 18$ years old; ineligible for surgery; had disease confined to one hemithorax, the mediastinum, contralateral hilar and supraclavicular (both ipsiand contralateral) lymph nodes; measurable disease according to RECIST 1.0 (10); no other clinically active cancer; no malignant pleural effusion (one negative cytology was required if pleural effusion was observed); no prior radiotherapy to the chest; WHO performance status $0-2$; leukocytes $\geq 3.0 \times 10^{9} / 1$; platelets $\geq 100 \times$ $10^{9} / \mathrm{l}$; bilirubin $<1.5 \times \mathrm{ULN}$; and creatinine $<125 \mu \mathrm{mol} / 1$.

All patients were to receive four courses of cisplatin plus etoposide and were randomised to receive TRT of either $45 \mathrm{~Gy}$ in 30 fractions (twice daily) or 42 Gy in 15 fractions (once daily) starting 3-4 weeks after start of the first chemotherapy course. Good responders were offered prophylactic cranial irradiation of $30 \mathrm{~Gy}$ in 15 fractions. There were no significant differences in overall response rates, progression free survival or overall survival (OS) (9). Thus, all patients were analysed as one cohort in the present study.

Patients were eligible for the present study provided the baseline staging CT scan was analysable, all pathological LNM were irradiated they completed TRT and at least one chemotherapy course.

TNM stage. Extent of disease was assessed according to the TNM v7 from contrast enhanced CT scans obtained before chemotherapy commenced. All CT scans were reviewed by a thoracic radiologist (MH). N3 disease was subcategorised as ipsilateral supraclavicular, contralateral supraclavicular, contralateral hilar and contralateral mediastinal LNM. An oncologist (TOH) and a medical physicist (NL) checked whether all pathological lesions on the CT scans were irradiated.

Analyses and statistical considerations. Survival time was defined as time from inclusion in the study until death and was estimated using the Kaplan-Meier method and compared using the log-rank test. Cox multivariate analyses were conducted adjusting for baseline characteristics (gender, age, performance status) $(11,12)$ and TRT schedule. The significance level was defined as $p<0.05$.

\section{Results}

Patients. From May 2005 until January 2011, 157 eligible patients were enrolled in the main trial. Of these, 144 $(91.7 \%)$ were analyzed in the present study. A total of 13 patients were excluded due to missing CT scans $(n=3)$, missing CT radiotherapy planning scans $(n=4)$, or incomplete TRT $(n=6)$. Patient characteristics are shown in Table I. Mean age was 63.5 years (range $=40-85$ years), 74 $(51.4 \%)$ were men, $121(84.0 \%)$ had PS $0-1,16(11.1 \%)$ had pleural fluid, $126(87.5 \%)$ completed all four chemotherapy courses and $65(45.1 \%)$ received TRT of $45 \mathrm{~Gy}$. Median follow up was 91.1 months (range=61.0-128.8 months) and 32 patients were alive at the time of the survival analyses (February 2016).

Stage of disease. Distribution of TNM stage is listed in Table II. Three patients $(2.1 \%)$ had stage I disease, 17 (11.8\%) stage II, 70 (48.6\%) stage IIIA, and $54(37.5 \%)$ stage IIIB. Consequently, stage I and II patients were analysed as one group.

Eighteen patients (12.5\%) had T1 tumour, 18 (12.5\%) T2, $42(29.2 \%) \mathrm{T} 3$ and $66(45.8 \%) \mathrm{T} 4$. Forty-one $(33.0 \%)$ patients had N0 disease, $13(9.0 \%) \mathrm{N} 1,53(36.8 \%) \mathrm{N} 2$ and $37(25.7 \%)$ N3 (Table III). N3 involvement included contralateral mediastinal LNM $(\mathrm{n}=25,17.4 \%)$, contralateral hilar LNM $(n=11,7.6 \%)$ and supraclavicular LNM $(n=15$, $10.4 \%$ ). Among the patients with supraclavicular LNM, 13 had ipsilateral while only two had contralateral LNM. Thus, these patients were analysed as one group. Twenty-five patients had LNM in one N3 region (17.4\%), 10 patients had in two $\mathrm{N} 3$ regions $(6.9 \%)$, and two had in three $\mathrm{N} 3$ regions (1.3\%) (Table III).

Survival analyses. In the whole cohort, median OS was 23.3 months and the 5-year survival was $26.4 \%$. There were no significant differences in median OS between men and women (21.8 vs. 25.1 months; $p=0.647)$, between PS $0-1$ and PS 2 patients (23.6 vs. 22.6 months; $p=0.365$ ), or those with pleural fluid $v s$. those without (31.0 vs. 22.6 months; $p=0.404$ ).

Patients with stage IIIB had significantly shorter median OS than those with lower disease stage (stage I-II: 33.8 months, IIIA: 33.0 months, IIIB: 18.8 months; $p=0.007$ ) (Table II, Figure 1).

Median OS for the different subcategories of N3 is listed in Table III. Patients with N3 disease $(n=37)$ had significantly shorter median OS compared with patients with N0-2 disease (16.7 months vs. 33.0 months; $p<0.001$ ) (Figure 1), but there 
Table I. Patient characteristics.

\begin{tabular}{|c|c|c|c|c|c|c|}
\hline & \multicolumn{2}{|c|}{ All patients $(n=144)$} & \multicolumn{2}{|c|}{ N0-2 $(n=107)$} & \multicolumn{2}{|c|}{ N3 $(n=37)$} \\
\hline & $\mathrm{n}$ & $\%$ & $\mathrm{n}$ & $\%$ & $\mathrm{n}$ & $\%$ \\
\hline \multicolumn{7}{|l|}{ Age, years } \\
\hline Mean, (SD), (range) & \multicolumn{2}{|c|}{$63.5 \pm 8.71,(40-85)$} & \multicolumn{2}{|c|}{$62.8 \pm 8.57(40-79)$} & \multicolumn{2}{|c|}{$65.6 \pm 8.9(44-85)$} \\
\hline \multicolumn{7}{|l|}{ Gender } \\
\hline Male & 74 & 51.4 & 51 & 47.7 & 23 & 62.2 \\
\hline Female & 70 & 48.6 & 56 & 52.3 & 14 & 37.8 \\
\hline \multicolumn{7}{|l|}{ Performance status } \\
\hline 0 & 47 & 32.6 & 40 & 37.4 & 7 & 18.9 \\
\hline 1 & 74 & 51.4 & 53 & 49.5 & 21 & 56.8 \\
\hline 2 & 23 & 16.0 & 14 & 13.1 & 9 & 24.3 \\
\hline \multicolumn{7}{|l|}{ Pleural fluid } \\
\hline Yes & 16 & 11.1 & 12 & 11.2 & 4 & 10.8 \\
\hline No & 128 & 88.9 & 95 & 88.2 & 33 & 89.2 \\
\hline \multicolumn{7}{|l|}{ Thoracic radiotherapy } \\
\hline $42 \mathrm{~Gy} / 15$ fractions & 79 & 54.9 & 60 & 56.1 & 19 & 51.4 \\
\hline $45 \mathrm{~Gy} / 30$ fractions & 65 & 45.1 & 47 & 43.9 & 18 & 48.6 \\
\hline \multicolumn{7}{|c|}{ Completed 4 courses of chemotherapy } \\
\hline Yes & 126 & 87.5 & 95 & 88.8 & 31 & 83.8 \\
\hline No & 18 & 12.5 & 12 & 11.2 & 6 & 16.2 \\
\hline
\end{tabular}

Table II. TNM stage.

\begin{tabular}{|c|c|c|c|c|c|c|}
\hline & No. of pts. $(n=144)$ & $\%$ & Median OS (months) & $95 \% \mathrm{CI}$ & $p$-Value & 5 -year survival $(\%)$ \\
\hline Stage I-II & 20 & 13.9 & 33.8 & $13.6-53.9$ & 0.007 & 40 \\
\hline \multicolumn{7}{|l|}{ Stage I } \\
\hline T1N0 & 1 & .7 & & & & \\
\hline T2NO & 2 & 1.4 & & & & \\
\hline \multicolumn{7}{|l|}{ Stage II } \\
\hline $\mathrm{T} 1 \mathrm{~N} 1$ & 4 & 2.8 & & & & \\
\hline $\mathrm{T} 2 \mathrm{~N} 1$ & 0 & 0 & & & & \\
\hline T3N0 & 13 & 9.0 & & & & \\
\hline Stage IIIA & 70 & 48.6 & 33.0 & $20.6-45.3$ & & 31.4 \\
\hline $\mathrm{T} 1 \mathrm{~N} 2$ & 9 & 6.3 & & & & \\
\hline $\mathrm{T} 2 \mathrm{~N} 2$ & 12 & 8.3 & & & & \\
\hline $\mathrm{T} 3 \mathrm{~N} 1$ & 7 & 4.9 & & & & \\
\hline $\mathrm{T} 3 \mathrm{~N} 2$ & 15 & 10.4 & & & & \\
\hline T4NO & 25 & 17.4 & & & & \\
\hline $\mathrm{T} 4 \mathrm{~N} 1$ & 2 & 1.4 & & & & \\
\hline Stage IIIB & 54 & 37.5 & 18.8 & $15.3-22.4$ & & 14.8 \\
\hline T1N3 & 4 & 2.8 & & & & \\
\hline $\mathrm{T} 2 \mathrm{~N} 3$ & 4 & 2.8 & & & & \\
\hline $\mathrm{T} 3 \mathrm{~N} 3$ & 7 & 4.9 & & & & \\
\hline T4N2 & 17 & 11.8 & & & & \\
\hline $\mathrm{T} 4 \mathrm{~N} 3$ & 22 & 15.3 & & & & \\
\hline
\end{tabular}

were no clinically relevant survival differences between the subcategories of N3: contralateral hilar LNM: 15.5 months (95\% CI=6.4-24.7), contralateral mediastinal LNM: 16.7 months $(95 \% \mathrm{CI}=9.2-24.1)$ and supraclavicular LNM: 15.1 months $(95 \% \mathrm{CI}=12.0-18.2)$. However, no patients with contralateral hilar LNM were alive after 5 years, while the corresponding numbers for those with supraclavicular and contralateral mediastinal LNM were $6.7 \%$ and $16.7 \%$. A statistical comparison was not performed since some patients had involvement of more than one $\mathrm{N} 3$ region. 

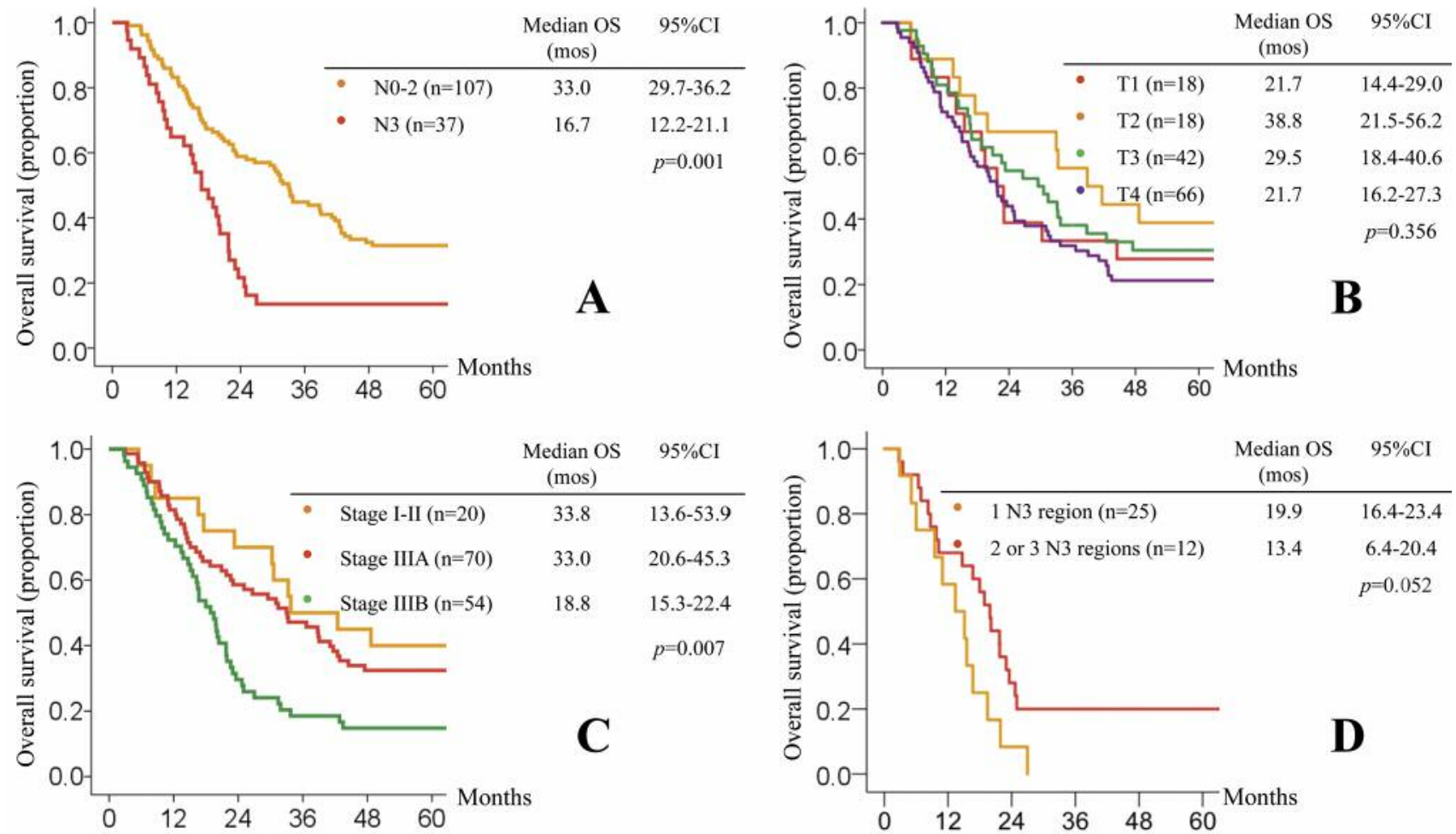

Figure 1. Kaplan-Meier survival plots for (A) NO-2 disease vs. N3 disease, $(B) T$ stage, $(C)$ stage of disease and $(D)$ involvement of one N3 region $v s$. two or three $N 3$ regions. $p$-Values were calculated using the log-rank test.

Table III. Median OS and 5-year survival for N3 lymph node metastases.

\begin{tabular}{|c|c|c|c|c|c|c|}
\hline & $\mathrm{N}$ & $\%$ & Median OS (months) & $95 \% \mathrm{CI}$ & $p$-Value & 5 -year survival $(\%)$ \\
\hline $\mathrm{T} 1$ & 18 & 12.5 & 21.7 & $14.4-29.0$ & 0.356 & 27.8 \\
\hline $\mathrm{T} 2$ & 18 & 12.5 & 38.8 & $21.5-56.2$ & & 38.9 \\
\hline $\mathrm{T} 3$ & 42 & 29.2 & 29.5 & $18.4-40.6$ & & 28.6 \\
\hline $\mathrm{T} 4$ & 66 & 45.8 & 21.7 & $16.2-27.3$ & & 21.2 \\
\hline N0-2 & 107 & 74.3 & 33.0 & $29.7-36.2$ & $0.001 *$ & 30.8 \\
\hline N3 & 37 & 25.7 & 16.7 & $12.2-21.1$ & & 13.5 \\
\hline Supraclavicular LNM & 15 & 10.4 & 15.1 & $12.0-18.2$ & & 6.7 \\
\hline Contralateral mediastinal LNM & 25 & 17.4 & 16.7 & $9.2-24.1$ & & 16.7 \\
\hline Contralateral hilar LNM & 11 & 7.6 & 15.5 & $6.4-24.7$ & & 0 \\
\hline One N3 station LNM & 25 & 17.4 & 19.9 & $16.4-23.4$ & 0.052 & 20.0 \\
\hline Two or three N3 station LNM & 12 & 8.3 & 13.4 & $6.4-20.4$ & & 0 \\
\hline
\end{tabular}

*Significantly different from N3.

There was a trend towards inferior median OS among the patients with involvement of more than one $\mathrm{N} 3$ region (one $\mathrm{N} 3$ region: 19.9 months, two or three N3 regions: 13.4 months; $p=0.052$ ) (Figure 1). Five-year survival for patients with involvement of one $\mathrm{N} 3$ region was $20.0 \%$ compared with $0.0 \%$ for those with involvement of two or three N3 regions (Table III).
There were no significant survival differences between the T categories (Table III, Figure 1). Median OS was 21.7 months for T1 tumours, 38.8 months for T2, 29.5 months for T3, and 21.7 months for T4 $(p=0.356)$.

Multivariate analyses showed that N3 disease $(\mathrm{HR}=1.94$; $95 \% \mathrm{CI}=1.27-3.0 ; p=0.002)$, stage of disease $(\mathrm{HR}=1.52$; $95 \% \mathrm{CI}=1.14-2.04 ; p=0.048)$, and involvement of $2-3 \mathrm{~N} 3$ 
regions $(\mathrm{HR}=3.61 ; 95 \% \mathrm{CI}=1.91-6.81 ; p=0.011)$ remained significant negative prognostic factors. None of the baseline characteristics, T stage, pleural fluid or TRT schedule were independent prognostic factors.

According to RECIST 1.1, lymph nodes with a short axis diameter of $\geq 15 \mathrm{~mm}$ are considered pathological. There were no significant differences when rerunning the analyses defining $\geq 15 \mathrm{~mm}$ as the criterium for pathological lymph nodes.

\section{Discussion}

In this study of patients with LD SCLC receiving concurrent chemo- and radiotherapy, we found that those with N3 disease had a significantly shorter survival than patients with N0-2 disease. There were no survival differences between the subcategories of $\mathrm{N} 3$ disease, but those with involvement of two or three $\mathrm{N} 3$ regions had significantly worse prognosis. To our knowledge, this is the first study reporting detailed $\mathrm{T}$ and $\mathrm{N}$ data including subcategories of $\mathrm{N} 3$ in a cohort of LD SCLC patients who all received standard chemotherapy and established schedules of concurrent thoracic radiotherapy. According to the authors, there were insufficient data to determine whether there were survival differences between the subcategories of N3 disease in the databases used for the 7 th and 8 th revision of the TNM for $\operatorname{SCLC}(7,8)$.

Our results may, in some aspects, differ from what was found in the article presenting the 8th revision of the TNM for SCLC (7). In that paper, $T$ stage was a significant prognostic factor among non-surgical patients, while $\mathrm{N}$ status was not, and there was no survival difference between stage IIIA and IIIB. The results are, however, not necessarily comparable since a large proportion of the patients in the TNM article had undergone surgery, and details on treatment was not available for all nonsurgical patients. We only analyzed non-surgical patients who received concurrent chemoradiotherapy.

A limitation of the study is the sample size, especially in the N3 subgroups. However, our sample size is still larger than the number of patients who received both chemotherapy and TRT in the database used for the latest TNM revision for SCLC (8th edition) (7). In this database $(n=5002)$ treatment data were available for only $11 \%$ of inoperable patients, and among these 2931 nonsurgical patients, it was only confirmed that 103 patients received both chemo- and radiotherapy.

Another limitation is that positron emission tomography (PET CT) was not used for staging of disease in our study. Studies conducted after our trial was initiated have shown that PET CT identifies pathological lesions better than CT scans, providing more accurate staging 13). However, few other published trials of TRT in LD SCLC have yet used PET CT for staging $(4,5,6,14)$.
Patient characteristics, TNM distribution and overall survival in our study cohort are similar to other studies of chemoradiotherapy in LD SCLC, $(4,5,6,14)$ we used the widest definition of LD (IASLC), (3) had no restrictions regarding comorbidity or age, and $16 \%$ had PS 2 . Thus, we consider the study population representative for LD SCLC patients receiving chemoradiotherapy.

We were not able to detect differences in survival between the subcategories of N3 disease. Thus, until other data emerge, it appears reasonable to consider all N3 disease as LD. The overall survival for all subcategories of N3 disease were longer than in studies of ED SCLC, (15) with the possible exception of patients with LNM to two or more N3 stations. It is also noteworthy that none of the patients with contralateral hilar LNM were alive after 5 years, but the number of patients was small. Our data suggest that incorporating the subcategories and number of involved N3 regions might add to the prognostic value of the TNM staging system, but this needs to be confirmed in larger cohorts. Furthermore, considering the improvement in staging methods with the introduction of PET CT and endobronchial ultrasound guided transbronchial needle aspiration, improved radiotherapy techniques, and the demonstrated benefit of TRT in some ED SCLC patients, the definition of patients who should be offered TRT may be challenged, but requires large databases containing detailed information about disease extent and treatment administered.

In conclusion, patients with N3 disease had inferior survival compared to those with N0-2 disease, but there were no survival differences between the N3 subcategories. Our study indicates that all N3 lymph node metastases should be considered as limited disease, with the possible exception of those with involvement of two or more N3 regions.

\section{Conflicts of Interest}

None.

\section{Acknowledgements}

The study was supported by the Central Norway Regional Health Authority (RHA), the Norwegian University of Science and Technology (NTNU) and the Norwegian Cancer Society.

\section{References}

1 Murray N and Turrisi AT, 3rd: A review of first-line treatment for small-cell lung cancer. J Thorac Oncol 1(3): 270-278, 2006.

2 Zelen M: Keynote address on biostatistics and data retrieval. Cancer Chemother Rep 34(2): 31-42, 1973.

3 Stahel R, Ginsberg R, Havemann K, Hirsch FR, Ihde DC, Jacek J, Karrer K, Maurer LH, Osterlind K and Houtte PV: Staging and prognostic factors in small cell lung cancer: a consensus report. Lung Cancer 5: 119-126, 1989. 
4 Kubota K, Hida T, Ishikura S, Mizusawa J, Nishio M, Kawahara M, Yokoyama A, Imamura F, Takeda K, Negoro S, Harada M, Okamoto H, Yamamoto N, Shinkai T, Sakai H, Matsui K, Nakagawa K, Shibata T, Saijo N and Tamura T: Etoposide and cisplatin versus irinotecan and cisplatin in patients with limitedstage small-cell lung cancer treated with etoposide and cisplatin plus concurrent accelerated hyperfractionated thoracic radiotherapy (JCOG0202): a randomised phase 3 study. Lancet Oncol 15(1): 106-113, 2014.

5 Schild SE, Bonner JA, Shanahan TG, Brooks BJ, Marks RS, Geyer SM, Hillman SL, Farr GH Jr., Tazelaar HD, Krook JE, Geoffroy FJ, Salim M, Arusell RM, Mailliard JA, Schaefer PL and Jett JR: Long-term results of a phase III trial comparing once-daily radiotherapy with twice-daily radiotherapy in limitedstage small-cell lung cancer. Int J Radiat Oncol Biol Phys 59(4): 943-951, 2004.

6 Turrisi AT, 3rd: Concurrent chemoradiotherapy for limited smallcell lung cancer. Oncology (Williston Park) 11(9 Suppl 9): 3137, 1997.

7 Nicholson AG, Chansky K, Crowley J, Beyruti R, Kubota K, Turrisi A, Eberhardt WE, van Meerbeeck J and Rami-Porta R: The International Association for the Study of Lung Cancer Lung Cancer Staging Project: Proposals for the Revision of the Clinical and Pathologic Staging of Small Cell Lung Cancer in the Forthcoming Eighth Edition of the TNM Classification for Lung Cancer. J Thorac Oncol 11(3): 300-311, 2016.

8. Shepherd FA, Crowley J, Van Houtte P, Postmus PE, Carney D, Chansky K, Shaikh Z and Goldstraw P: The International Association for the Study of Lung Cancer lung cancer staging project: proposals regarding the clinical staging of small cell lung cancer in the forthcoming (seventh) edition of the tumor, node, metastasis classification for lung cancer. J Thorac Oncol 2(12): 1067-1077, 2007

9 Gronberg BH, Halvorsen TO, Flotten O, Brustugun OT, Brunsvig PF, Aasebo U, Bremnes RM, Tollali T, Hornslien K, Aksnessaether BY, Liaaen ED and Sundstrom S: Randomized phase II trial comparing twice daily hyperfractionated with once daily hypofractionated thoracic radiotherapy in limited disease small cell lung cancer. Acta Oncol 55(5): 591-597, 2016.
10 Therasse P, Arbuck SG, Eisenhauer EA, Wanders J, Kaplan RS, Rubinstein L, Verweij J, Van Glabbeke M, van Oosterom AT, Christian MC and Gwyther SG: New guidelines to evaluate the response to treatment in solid tumors. European Organization for Research and Treatment of Cancer, National Cancer Institute of the United States, National Cancer Institute of Canada. J Natl Cancer Inst 92(3): 205-216, 2000.

11 Kasmann L, Janssen S and Rades D: Karnofsky Performance Score, Radiation Dose and Nodal Status Predict Survival of Elderly Patients Irradiated for Limited-disease Small-cell Lung Cancer. Anticancer Res 36(8): 4177-4180, 2016.

12 Kasmann L, Janssen S and Rades D: Prognostic Factors Including the Expression of Thyroid Transcription Factor 1 (TTF1) in Patients Irradiated for Limited-disease Small Cell Lung Cancer. Anticancer Res 36(7): 3499-3503, 2016.

13 Ambrosini V, Nicolini S, Caroli P, Nanni C, Massaro A, Marzola MC, Rubello D and Fanti S: PET/CT imaging in different types of lung cancer: an overview. Eur J Radiol 81(5): 988-1001, 2012.

14 Takada M, Fukuoka M, Kawahara M, Sugiura T, Yokoyama A, Yokota S, Nishiwaki Y, Watanabe K, Noda K, Tamura T, Fukuda $\mathrm{H}$ and Saijo N: Phase III study of concurrent versus sequential thoracic radiotherapy in combination with cisplatin and etoposide for limited-stage small-cell lung cancer: results of the Japan Clinical Oncology Group Study 9104. J Clin Oncol 20(14): 3054-3060, 2002.

15 Sun Y, Cheng Y, Hao X, Wang J, Hu C, Han B, Liu X, Zhang L, Wan H, Xia Z, Liu Y, Li W, Hou M, Zhang H, Xiu Q, Zhu Y, Feng J, Qin S and Luo X: Randomized phase III trial of amrubicin/cisplatin versus etoposide/cisplatin as first-line treatment for extensive small-cell lung cancer. BMC Cancer 16(1): 265, 2016. 